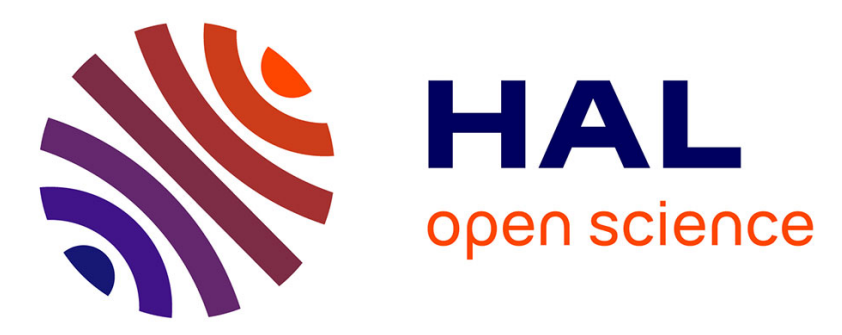

\title{
Membrane patterned by pulsed laser micromachining for proton exchange membrane fuel cell with sputtered ultra-low catalyst loadings
}

S Cuynet, A Caillard, S Kaya-Boussougou, T Lecas, N Semmar, J Bigarré, P Buvat, Pascal Brault

\section{To cite this version:}

S Cuynet, A Caillard, S Kaya-Boussougou, T Lecas, N Semmar, et al.. Membrane patterned by pulsed laser micromachining for proton exchange membrane fuel cell with sputtered ultra-low catalyst loadings. Journal of Power Sources, 2015, 298, pp.299-308. 10.1016/j.jpowsour.2015.08.019 . hal01186345

\section{HAL Id: hal-01186345 \\ https://hal.science/hal-01186345}

Submitted on 24 Aug 2015

HAL is a multi-disciplinary open access archive for the deposit and dissemination of scientific research documents, whether they are published or not. The documents may come from teaching and research institutions in France or abroad, or from public or private research centers.
L'archive ouverte pluridisciplinaire HAL, est destinée au dépôt et à la diffusion de documents scientifiques de niveau recherche, publiés ou non, émanant des établissements d'enseignement et de recherche français ou étrangers, des laboratoires publics ou privés. 


\title{
Membrane patterned by pulsed laser micromachining for proton exchange membrane fuel cell
} with sputtered ultra-low catalyst loadings

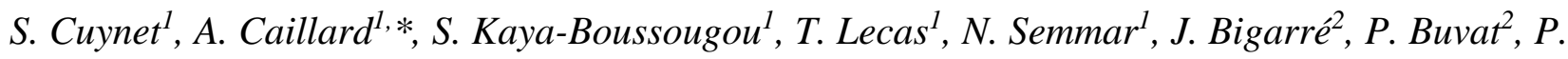
Brault $^{1}$

${ }^{1}$ Groupe de Recherches sur 1'Energétique des Milieux Ionisés (GREMI), UMR7344 Université d'Orléans - CNRS BP6744, F-45067 Orléans Cedex 2, France

${ }^{2}$ CEA-DAM, Le Ripault, BP16, F-37260, Monts, France

* CORRESPONDING AUTHOR : amael.caillard@ @univ-orleans.fr, +33 (0)2 38494352

KEYWORDS. Proton exchange membrane fuel cells; Platinum catalyst loading; Patterned membrane electrode assembly.

\begin{abstract}
.
Proton exchange membranes were nano- and micro-patterned on their cathode side by pressing them against stainless steel molds previously irradiated by a Ti:Sapphire femtosecond laser. The membranes were associated to ultra-low loaded thin catalytic layers $\left(25 \mu \mathrm{g}_{\mathrm{Pt}} \mathrm{cm}^{-2}\right)$ prepared by plasma magnetron sputtering. The Pt catalyst was sputtered either on the membrane or on the porous electrode. The fuel cell performance in dry conditions were found to be highly dependent on the morphology of the membrane surface. When nanometric ripples covered by a Pt catalyst were introduced on the surface of the membrane, the fuel cell outperformed the conventional one with a flat membrane. By combining nano- and micro-patterns (nanometric ripples and 11-24 $\mu \mathrm{m}$ deep craters), the performance of the cells was clearly enhanced. The maximum power density achieved by the fuel cell was multiplied by a factor of 3.6 (at $50{ }^{\circ} \mathrm{C}$ and 3 bars): $438 \mathrm{~mW} \mathrm{~cm}^{-2}$ vs $122 \mathrm{~mW} \mathrm{~cm}^{-2}$. This improvement is due to high catalyst utilization with a high membrane conductivity. When Pt is sputtered on the porous electrode (and not on the membrane), the contribution of the patterned membrane to the fuel cell efficiency was less significant, except in the presence of nanometric ripples. This result suggests that the patterning of the membrane must be consistent with the way the catalyst is synthesized, on the membrane or on the porous electrode.
\end{abstract}




\section{Introduction}

Proton exchange membrane fuel cells (PEMFC) are attracting increasing research interest as they have a great potential as clean-energy power sources for portable, transportation and stationary applications owing to their high power densities, low temperature operation and zero greenhouse-gas emissions. The membrane electrode assembly (MEA) is the main component of the PEMFC. It consists of a proton exchange membrane (PEM), two catalytic layers and two gas diffusion layers (GDL). Nafion membranes are the most popular electrolytes due to their excellent proton conductivity, their mechanical and their chemical stability. The catalytic layer where proton, electronic, and fuel transfers occur is still the subject of intense research. These components are typically fabricated individually and then pressed together at high pressure and high temperature. While significant progress has been achieved in recent decades, the high cost of PEMFCs (materials and fabrication process) is one of the main obstacles preventing their commercial application. One of the approaches to overcome the cost issue is to reduce the most widely used electrocatalyst, platinum $(\mathrm{Pt})$, to maximize the surface area of the Pt catalyst and to enhance its use without sacrificing cell performance. This will help to minimize the fuel cell size and the amount of materials required to build an efficient fuel cell. The use of sputter deposition can reduce the catalyst loading by increasing the increase its mass activity [1-6], but performance is still reduced in terms of area specific power density (expressed in $\mathrm{mW} \mathrm{cm}^{-2}$ ). When the Pt thin film is formed on the membrane by sputtering (a fuel cell architecture called catalyst coated membrane, CCM), the fuel cell reaches about half the power density of a commercial MEA (about $0.5 \mathrm{~W} \mathrm{~cm}^{-2}$ against $1 \mathrm{~W} \mathrm{~cm}^{-2}$ ) with one-twentieth of the platinum loading on the cathode side (typically $20 \mu \mathrm{g}_{\mathrm{Pt}} \mathrm{cm}^{-2}$ against $400 \mu \mathrm{g}_{\mathrm{Pt}} \mathrm{cm}^{-2}$ ), which increases the mass specific power density by a factor of 10 (typically $25 \mathrm{~W} \mathrm{mg}^{-1}$ against $2.5 \mathrm{~W} \mathrm{mg}^{-1}$ ).

To improve the performance of fuel cells in which the membrane is Pt-coated by sputtering, one approach is to optimize the interface between the membrane and the catalytic layer of the cathode, where the sluggish oxygen reduction reaction (ORR) occurs. This interface should be built in such a way that electrons, protons and the gas molecules can have easy access to the catalytic sites. For example, the Pt catalyst must be 
deposited on a support that allows a good interaction with the Nafion ionomer, encouraging proton access to the Pt catalyst sites and not disturbing the diffusion of the gaseous species. In addition, the MEA must exhibit excellent bonding between the electrodes and the membrane to minimize electrical losses, while ensuring high mechanical strength to promote durability. One strategy to satisfy such conditions is to tailor the morphology of the catalyst layer-Nafion interface by promoting a high contact area between the catalyst and the membrane, which may facilitate proton migration (high proton conductivity), and access to the catalyst, decrease interfacial resistance and even enhance the water retention capability of the membrane. This concept can be realized by the direct sputter deposition of Pt catalyst particles on nano/micro-scale structures previously formed on the membrane surface.

Recent studies seem to indicate that the patterning of PEM enhances the fuel cell performance, especially with the use of different techniques to generate a surface - patterning structure. These include surface roughening by abrasion [7], by the introduction of a rough transition Nafion thin film [8,9], by plasma treatments [10-14] and by the use of (optic, electronic) lithography [15-21]. One of the first attempts to pattern the surface of a Nafion membrane was made in 2002 by O'Hayre et al. [7] who abraded the membrane by using SiC sandpaper to obtain fine and coarse roughening. This textured surface disrupted the sputtered platinum film. It was found that fuel cell performance was extremely sensitive to membrane texture [7]. However, some SiC impurities can be present on the surface of the membrane after abrasion which can disturb the electrochemical reactions. Wang et al. [9] introduced a rough Nafion thin film between the catalyst layer and the membrane using the spray technique to fabricate a direct methanol fuel cell. The rough interface reduced the contact resistance and expanded the reaction region of MEA, significantly improving of the fuel cell performance. In addition, the modified structure also exhibited a better durability due to the enhancement of interaction between electrode and membrane compared to the normal CCM structure. The membrane was also treated by argon ions and plasma to enlarge the effective area of the electrode/cathode interfaces. Cho et al. [12, 13] demonstrated that the roughness and hydrophobicity of the membrane surface increased with increasing argon ion density, which is favored for 
a high-performance PEMFC. In fuel cell tests, one MEA based on a roughened Nafion® membrane exhibited a maximum power density, which was two times higher than that of the single cell employing an untreated Nafion® 115 membrane. Kim et al. [14] used less expensive atmospheric-pressure glow plasma in a gas mixture of $\mathrm{He} / \mathrm{H}_{2}$ to etch the Nafion surfaces very efficiently. By using $\mathrm{SiC}$ abrasion, by the introduction of the rough thin film of Nafion or by subjecting the membrane to plasma/ion bombardment, no regular or ordered patterns are formed and the surface of the membrane resembles a creased paper, especially when abrasion is used.

In order to obtain ordered patterns on the membrane and thus a better understand the influence of pattern dimensions on the fuel cell activity, different patterning techniques using lithography were introduced in the mid-2000s. For most of these techniques, master molds having regular and ordered patterns on their surface are required. These patterns are then transferred to the membrane by hot pressing or by casting. The molds are previously fabricated by coupling lithography to produce a patterned mask and plasma etching. For example, Aizawa et al. $[15,16]$ fabricated ordered hole structures on the polished side of an Si wafer using optical lithography and the Bosh etching process before casting the ionomer solution over the Si mold to form an ordered micro pillar-array patterned Nafion membrane. With this technique, they were able to control the pillar widths and heights. Each pillar had micrometric dimensions, the same average width of about $2 \mu \mathrm{m}$ and different average heights of about 3,6 and $10 \mu \mathrm{m}$. To reduce these dimensions, one dimensional nanometric $\mathrm{SiO}_{2}$ grating molds were formed by Taylor et al. [17] using the electron beam lithography technique. Identical techniques were used by Yildrim et al. [18] to form molds consisting of a one dimension grating (channel width $19 \mu \mathrm{m}$ and distance between two features $25 \mu \mathrm{m}$ ), but the transfer of the patterns to the membrane was achieved by hot pressing (also called hot embossing). This transfer technique has been also used to transfer patterns from two micrometric stainless steel meshes on both sides of a Nafion N115 membrane [19]. To avoid the need for a mold, Omosebi et al. [20,21] demonstrated the patterning of persulfonic Nafion membranes using electron beam lithography coupled with dry etching. Lithography was used to define the pattern structure on the membrane (and not on the mold) whereas a plasma based on a mixture of $\mathrm{O}_{2}$ and $\mathrm{CHF}_{3}$ gas allowed the direct etching of the membrane through a 
germanium mask. Although optical or electronic lithography can be used to form ordered patterns on the membrane surface, some studies claim that these methods have certain limitations such as high cost and a complicated fabrication method. Chi et al. [22] developed a process to form $1 \mu \mathrm{m}$ surface patterned Nafion films by using different types of $\mathrm{ZnO}$ nanorods as templates. They obtained a $59 \%$ increase in the power density in a PEMFC when using the surface-patterned MEA with the highest surface area. Li et al. [23] introduced mesopores to Nafion membranes via a soft template method using either non-ionic block copolymer or a colloidal silica mediated self-assembly technique. With the second technique, the highly ordered and periodic mesoporous Nafion significantly enhanced the water retention capability and had a higher proton conductivity particularly at reduced relative humidity as compared with the pristine Nafion. In addition, Zhou et al. [24] used liquid precursors to form micro-patterned PEM with micrometric features by using soft lithographic/micromolding techniques. They used patterned sacrificial templates made from poly(cyanomethyl-acrylate) films which were patterned by soft-lithography techniques using a PFPE mold. Finally, Wang et al. [25] developed a novel MEA in which both the cathode and the membrane were incorporated in a porous PTFE matrix.

All these studies aimed to increase the fuel cell power density by increasing the surface area of the membrane (especially for CCM architecture) and where not concerned with reducing the catalyst loading. O'Hayre et al. [7] attempted to decrease the catalyst loading in the cathode by enlarging the surface area of the membrane, but the method did not introduce regular and ordered patterns and could introduce $\mathrm{SiC}$ impurities on the membrane, making it rather difficult to interpret the influence of the pattering surface. Moreover, some of the studies dealing with the formation of ordered patterns report the possibility of producing scalable patterns from nanometric to micrometric size. The superposition of nano- and micropatterns on a unique membrane has not been pointed out in the literature. As a result, the aim of the present study is to associate Pt catalyst deposition by plasma sputtering and a Nafion membrane imprinted by nanoand micro-patterns in order to increase the performance of fuel cells containing ultralow loading of $\mathrm{Pt}$ 
catalyst. Micromolding and pulsed laser micromachining were used to imprint the membrane with ordered patterns.

\section{Experimental}

\section{Preparation of patterned membranes}

The patterned membranes were imprinted by transferring the patterns of stainless steel (SS) molds to Nafion NR212 membranes. Four different shapes of patterns were used for the membrane imprint. Each master SS mold consisted of a piece of polished SS with an area of $50 \mathrm{~mm} \times 50 \mathrm{~mm}$ on which the nano- and micropatterns were imprinted on an area of $23 \times 23 \mathrm{~mm}$ using a titanium-doped sapphire femtosecond pulsed laser (centered on $790 \mathrm{~nm}$ ). Figure 1 shows the overall fabrication procedure for surface-patterned Nafion membranes. Before and after laser irradiation, all the pieces of SS were successively degreased in acetone and ethanol. To prepare the four molds, the pulse frequency and the laser pulse duration were fixed at 100 $\mathrm{Hz}$ and $100 \mathrm{fs}$, respectively. A mean power of $200 \mathrm{~mW}$ was used for the nano-patterned mold nanoSS200, whereas the mean powers were successively fixed at 50, 100 and $200 \mathrm{~mW}$ for the three micro-patterned molds: $\mu S S 50, \mu S S 100$ and $\mu S S 200$. The nanoSS200 mold consists of an array of laser impacts spaced by $30 \mu \mathrm{m}$.

As reported in the literature [26-28] various nanometer patterns are expected due the formation of sub wavelength ripples on the surfaces of the mold irradiated with a few fs laser pulses. The number of laser impacts on the same spot at $200 \mathrm{~mW}$ was increased from 1 to 20 for the $\mu S S 50$ mold in order to fabricate micrometric holes in the SS substrate. The number of impacts was increased up to 21 and 24 when the mean power of the laser pulse was respectively fixed at 100 and $50 \mathrm{~mW}$. These conditions lead to adjusting the value of the cumulative laser fluence close to $8850 \mathrm{~J} \mathrm{~cm}^{-2}$ for the micrometer patterns. The space period between each hole varies between 17, 22 and $30 \mu \mathrm{m}$ for the three molds, $\mu$ SS50, $\mu$ SS 100 and $\mu$ SS200, respectively. All the main parameters used for carving (writing) these four molds are presented in Table 1. Before making the three arrays of micro-patterns on the large area $(23 \times 23 \mathrm{~mm})$, a unique micro-pattern (on the same spot) was also realized for the three mean powers on polished SS. 
The four molds were used to imprint the cathode side of four Nafion NR212 membranes (dry thickness of $51 \mu \mathrm{m})$. Each membrane $(40$ x $40 \mathrm{~mm}$ ) was pressed between a polished SS and a patterned SS mold under $16 \mathrm{kN} \mathrm{cm}^{-2}$ at ambient temperature during $5 \mathrm{~min}$. To prevent any damage to the membrane during its extraction from the patterned SS mold, the membrane was clamped on the polished SS using a homemade

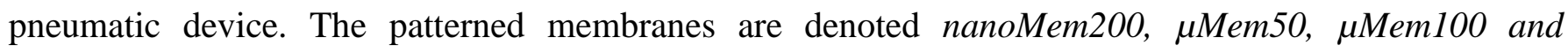
$\mu$ Mem200.

The size and the morphology of the positive nano- and micro-patterns on the mold and of the negative nanoand micro-patterns on the imprinted membrane were analyzed with a Zeiss SUPRA 40 scanning electron microscope with an electron energy beam of $5 \mathrm{keV}$ and by a VHX-100 Keyence digital optical to measure the specific surface after membrane patterning (only at the micrometer scale). This gives a $A_{s} / A_{g}$ ratio with the specific surface $A_{s}$ of the patterning membrane and the geometric surface $A_{g}$ of the membrane.

\section{Electrode with sputtered ultra-low catalyst loadings}

Two sorts of catalyst layer were prepared by plasma sputtering deposition. To generate the first catalyst layer, a solid disk of platinum (99.999\%) was sputtered by argon ions in a vacuum chamber and the sputtered platinum atoms condensate on the cathode side of the patterned membrane NR212. This first cathode catalyst layer is denoted catalyst-coated membrane (CCM). The sputter coating was also applied on a gas diffusion layer (GDL) for the second catalyst layer. The $400 \mu \mathrm{m}$ thick GDL used in this study is the 10 BC (SGL, Germany) for the cathode and the anode. This GDL consists of a carbon fiber matrix covered by a microporous layer (MPL) on one side composed of PTFE (5 wt\% PTFE) and carbon black. This second catalyst layer is called the catalyst-coated backing (CCB).

The plasma deposition chamber consisted of a 20-L cross shaped chamber pumped by a primary pump (Adixen ACP5) and a turbo-molecular pump (Adixen ATH500M). The solid disk made of platinum was 
clamped on a 2-inch plasma source called a magnetron (Angström sciences Inc. ONYX2) powered by a DC power supply (Advances Energy, pinnacle plus). The membrane or the GDL (for the first and second catalyst layer, respectively) was fixed on a substrate holder placed $50 \mathrm{~mm}$ in front of the platinum target. Rotation during the deposition process ensured thickness homogeneity. For each deposition run, the argon pressure, the argon flow rate and the DC power were set to $10^{-2} \mathrm{mbar}, 4 \mathrm{sccm}$ (standard cubic centimeter per minute) and $50 \mathrm{~W}$, respectively. For these deposition parameters, the deposition rate (per unit geometric area) previously measured by Rutherford backscattering spectroscopy (RBS) was $50 \mu \mathrm{g}_{\mathrm{Pt}} \mathrm{cm}^{-2} \min ^{-1}$. The sputtering time was adjusted to obtain a Pt loading of $25 \mu \mathrm{g}_{\mathrm{Pt}} \mathrm{cm}^{-2}$ on each cathode (patterned membrane or GDL) and $20 \mu \mathrm{g}_{\mathrm{Pt}} \mathrm{cm}^{-2}$ on the anode GDL. The apparent active surface for the anode and cathode side was $5 \mathrm{~cm}^{2}(22.3 \times 22.3 \mathrm{~mm})$

\section{MEA preparation and fuel cell characterizations}

Two sets of four patterned membranes were tested in real fuel cell conditions. Each set of membranes was used to build four CCM and four CCB fuel cells. Two GDL were placed on both sides of each nonprehumidified Nafion membrane. One surface of the membrane had regularly ordered patterns, while the other was flat. We used the patterned and flat sides for the cathode and anode sides, respectively. For the CCM fuel cells, the patterned surface of the membrane was covered by Pt catalyst, so the cathode GDL was uncatalyzed (conversely for CCB). Two membranes with flat surfaces (un-pressed) on both sides were used to fabricate one CCM MEA and one CCB MEA by applying the same procedure. These two MEA are considered as references and are called $C C M \_$flatMem and $C C B \_f l a t M e m$. The ten asymmetric membrane electrode assemblies were mechanically pressed at $2 \mathrm{Nm}$ torque between two bipolar plates and two 200 $\mu \mathrm{m}$ thick gaskets in a commercial $5 \mathrm{~cm}^{2}$ cell (Paxitech). Oxygen and hydrogen gases were introduced in the PEMFC fuel cell without humidification, which defines dry conditions for the fuel cell test experiments.

Gas flow rates and backpressure were regulated by mass flow controllers and pressure controllers (Bronkhorst), the gas stoichiometric flow rates were adjusted to $2 \mathrm{sccm}$, except for current density lower 
than $0.1 \mathrm{~A} \mathrm{~cm}^{-2}$ where $6 \mathrm{sccm}$ were applied on both sides of the fuel cell. The oxygen flow rate was half of the hydrogen flow rate. The fuel cell was connected to an electric load (Amrel, Series Zero-Volt Programmable Loads) operating in a constant voltage mode. A homemade procedure ensuring a quick and efficient use of the MEAs. During the first three hours of operation, voltage pulses between $0.35 \mathrm{~V}$ and 0.8 $\mathrm{V}$ at $1 \mathrm{~Hz}$ were applied on the fuel cell and the delivered current density was recorded on a PC. This set up comprised 3 steps in which the temperature and the absolute backpressure were modified: $30{ }^{\circ} \mathrm{C}$ at 1.1 bar, $30{ }^{\circ} \mathrm{C}$ at 2 bar and $50{ }^{\circ} \mathrm{C}$ at 2 bar during the first half hour, one hour later and an hour and a half at the end, respectively. Once the pulsed mode was finished, the cell was conditioned at $50{ }^{\circ} \mathrm{C}$ at 2 bar prior to recording the polarization curves (cell voltage $E$ vs current density $j$ ). To obtain the curves, the cell voltage was progressively decreased from the OCV (Open circuit voltage) to $200 \mathrm{mV}$ with a step voltage of $50 \mathrm{mV}$ and a step duration of $30 \mathrm{~s}$, respectively. During this voltage ramp, the current delivered by the cell through an electronic load was recorded. The polarization curves were treated using the method developed by Ticianelli et al. [29] and Hirano et al. [30] in order to extract some kinetic data. The following equations were used:

$E=E_{r}-b \log \left(j / j_{0}\right)-R_{\text {cell }} j$

where $j$ is the current density at the potential $E, E_{r}$ the reversible potential of the cell, $j_{0}$ and $b$ the exchange current density and Tafel slope for ORR, respectively, and $R_{\text {cell }}$ is the total resistance causing the linear variation in the cell potential versus current density $(j)$. This treatment was possible assuming that mass transport limitations and activation overpotentials at the hydrogen electrode were negligible and we investigated the oxygen reduction reaction kinetics by analyzing the polarization data for low current densities, $j<0.5 \mathrm{~A} \mathrm{~cm}^{-2}$, where the mass transfer effects were negligible. Because $\mathrm{E}_{\mathrm{r}}$ and $\mathrm{b}$ were found to be almost constant for all tested MEA, only the values of $j_{0}$ and $\mathrm{R}_{\text {cell }}$ were reported in this study.

\section{Results and Discussion}

Morphological characteristics of the patterned molds and membranes 
Figure 2 compares the surface morphology of the four SS molds obtained by SEM and for different laser parameters. From the SEM analysis, a coarse difference in morphology was found. The first SEM micrograph corresponding to the nanoSS200 shows laser-induced periodic surface structures (LIPSS) after consecutive (i.e. accumulative) pulsed femtosecond laser irradiation (especially visible in the inset). The period of the observed structures is much smaller that the laser beam wavelength (from 265 to $500 \mathrm{~nm}$, against $790 \mathrm{~nm}$ for the beam wavelength). Such a small period has already been reported in the literature $[31,32]$ for metal surfaces Dark periodic circular areas (diameter of about $15 \mu \mathrm{m}$ ) appear on this micrograph and correspond to the laser spots but no visible craters were produced after a single laser pulse.

The surface of the $\mu S S 50$ mold on figure $2 \mathrm{~b}$ displays regular periodic ablation craters. These craters are not perfectly circular: the diameter reaches $10 \mu \mathrm{m}$ along the vertical axis and $5 \mu \mathrm{m}$ along the horizontal axis. As indicated on the figure, a bump of ejected material is observed in the center of each square area defined by four craters (dashed square on figure 2b). LIPSS are visible between each crater horizontal lines. The inserted image displays a SEM micrograph corresponding to unique laser craters obtained after 24 pulses. No laser scanning was carried out here, a single area was irradiated. This crater is hemi-spherical and its diameter reaches $13.1 \mu \mathrm{m}$, which is larger than the dimensions of the periodic craters obtained after laser scanning. The unique crater is surrounded by a $24 \mu \mathrm{m}$ diameter circular bump (corresponding to matter ejected during the ablation pulses) and a $75 \mu \mathrm{m}$ diameter halo. The laser craters become larger when the laser power increases as displayed on the SEM pictures corresponding to the $\mu S S 100$ and $\mu S S 200$ molds (figure $2 \mathrm{c}$ and $2 \mathrm{~d}$, respectively). In the insets, the diameters of the unique circular craters reach 17 and 24 $\mu \mathrm{m}$, whereas the diameters of the periodic circular craters are close to 11 and $23 \mu \mathrm{m}$, respectively. Nanometric LIPSS are visible on the $\mu$ SS100 but not well defined on the $\mu S S 200$ molds. When a unique laser crater is formed on SS, the circular bump and the halo are still visible but all the diameters (crater, circular bump and halo) increase with the laser power. 
The patterns formed by laser irradiation were transferred to the membrane by high pressure imprinting. Figure 3 displays the micrographs obtained by SEM (a-d) and by digital optical microscope (e-g) for the four membranes (nanoMem200, $\mu$ Mem50, $\mu$ Mem100 and $\mu$ Mem200). The negative of each pattern is well transferred to the membrane. The bumps correspond to the laser craters and the holes correspond to the mold bumps. On each patterned membrane, a circular spot with a smooth surface appears on the top of each bump surrounded by a rough surface (not so visible on the nanoMem200). The diameter of these smooth spots is slightly smaller than the diameter of the laser crater previously observed on the $\mu S S$ molds (about $20 \%$ smaller). The pictures obtained by optical microscope give a 3D overview of the membrane surface. On the $\mu$ Mem50 and the $\mu$ Mem100 membrane, the bumps (in orange) are not well separated along the $\mathrm{X}$ axis.

The increase in the membrane surface after patterning is given on each image. The surfaces of the three patterned membranes ( $\mu$ Mem50, $\mu$ Mem100 and $\mu$ Mem5200) increased by a factor $A_{s} / A_{g}$ of $1.51,1.60$ and 1.89 , respectively. The three $\mu S S$ patterned molds generate deep indents on the membrane; i.e. 11,14 and $24 \mu \mathrm{m}$ for the $\mu S S 50, \mu S S 100$ and $\mu S S 200$ molds, respectively. The optical microscope is not sensitive to nanometric patterns and only the micro-patterns are observed. As a result, the surface of the nanoMem200 membrane cannot be measured properly and the increase in surface for the other three membranes $\mu \mathrm{Mem}$ will remain underestimated. The surfaces of the SS molds were previously measured using the same procedure. Table 2 presents the main dimensional parameters of the four SS molds and of the four membranes found from the analysis of the micrographs. Because the bump diameters on the membrane are difficult to define properly, they are not given in the table. It appears that the surfaces of the membranes are lower than those of the molds. Moreover, the craters on the SS molds are higher than the bumps on the membranes. The differences in surface increase and in pattern size between the mold and the membrane indicate that the membranes do not entirely fill the craters during the transfer occurring at low temperature. The top of each bump on the membrane is not pressed against the molds, which explains its smooth surface. 


\section{Fuel cell characterizations}

The four patterned membranes and the flat membrane were tested in ten asymmetric MEA : five MEA with CCM architectures and 5 MEA with CCB architectures. Figure 4 displays the first three hours of CCM fuel cell operation. For the MEA based on a standard flat membrane NR212, current at the beginning of the start-up procedure is low $\left(0.2 \mathrm{~A} \mathrm{~cm}^{-2}\right.$ at $\left.0.3 \mathrm{~V}\right)$ but it continuously increases up to more than $1.5 \mathrm{~A} \mathrm{~cm}^{-2}$ at $50{ }^{\circ} \mathrm{C}, 2$ bars. This phenomenon is attributed to a better anode and membrane hydration and to catalyst reorganization. For the MEA based on a patterned membrane, two different behaviors can be observed. CCM_MMem100 and CCM_nanoMem200 MEAs show a rapid current increase in the first 5 minutes followed by a slower current evolution, whereas for $C C M \_\mu M e m 50$ and $C C M \_\mu M e m 200$ MEAs, a quick current decrease appears in the first 5 minutes. This is probably due to electrode flooding, a good contact between membrane and electrode is needed in order to evacuate the water produced at the cathode and to hydrate the anode throw membrane. Depending on the surface micro-patterned (crater depth and crater diameter), the membrane-electrode contact at the bottom of the crater may be less good and some voids can occur. Then, after this transient period, the starting procedure has little effect on the current increase for these AMEs.

Nevertheless, during the procedure, all the MEA based on a patterned membrane give a higher current than the MEA based on a standard flat membrane NR212. The highest current is given by the CCM $C C M \_\mu M e m 100$ (pink). The current delivered by this MEA is more than two times higher than the current delivered by the reference MEA CCM_flatMem (red). The MEA CCM_nanoMem200 (blue) containing the nanoMem200 membrane gives the lowest current of all the MEA based on a patterned membrane. At 0.35 V, the lowest to the most powerful MEA are: CCM_flatMem $<C C M \_n a n o M e m 200<C C M \_\mu M e m 50<$ $C C M \_\mu M e m 200<C C M \_\mu M e m 100$.

Figure 5 shows the polarization curves of the five CCM MEAs after the pulsed mode for two testing conditions: $50{ }^{\circ} \mathrm{C}$ at 2 bars (a) and $50{ }^{\circ} \mathrm{C}$ at 3 bars (b). All MEAs are leak-proof and the open current voltage 
$(\mathrm{OCV})$ is around $0.94 \mathrm{~V}$ for all samples. In comparison with commercial MEA, this low value is due to the ultralow catalyst loading. However, the patterning does not affect the OCV and the hydrogen crossover remains very low. The presence of a patterned membrane significantly improves the power density compared to the presence of a flat commercial membrane. The shape of the micro-patterns affects the cell performance. Over all the current densities, the $C C M \_\mu M e m 100$ membrane delivers to the highest voltage. For a backpressure of 2 bar, the current densities at $0.65 \mathrm{~V}$ are $36,126,262,278$ and $328 \mathrm{~mA} \mathrm{~cm}{ }^{-2}$

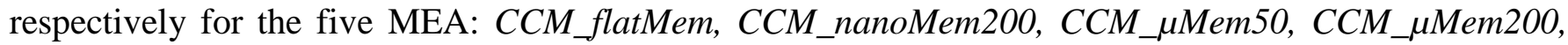
$C C M \_\mu M e m 100$. The respective maximum power densities Pmax are 58, 150, 250, 230 and $307 \mathrm{~mW} \mathrm{~cm}^{2}$. For higher backpressure (3 bar), the Pmax values are markedly increased. The MEA CCM_ able to deliver $438 \mathrm{~mW} \mathrm{~cm}^{-2}$ whereas $122 \mathrm{~mW} \mathrm{~cm}^{-2}$ are obtained with a flat membrane based MEA.

Table 3 gives the values of the total resistance $R_{\text {cell }}$ and of the exchange current density $j_{0}$ for all tested MEA, no significant effect were visible on the $\mathrm{E}_{\mathrm{r}}$ and $\mathrm{b}$ parameters in the kinetic region of the polarization curves (i.e. in the low current density region, $\mathrm{j}<0.5 \mathrm{~A} \mathrm{~cm}^{-2}$ ). Although the same amount of catalyst was used for all MEA, the jo values are modified and it expected to be due to the presence of the patterns on the membrane. The flatMem membrane (and to a lesser extent the nanoMem200 membrane) leads to a strong voltage drop at low current density and so low exchange current density $\mathrm{j}_{0}\left(<10^{-7} \mathrm{~A} \mathrm{~cm}^{-2}\right)$. This reveals the poor catalytic surface obtained by the sputter coating of platinum on a flat membrane or on a nano-patterned membrane. The $\mathrm{j}_{0}$ values are improved by the presence of micro-patterns on the membranes before the platinum coating and $810^{-7} \mathrm{~A} \mathrm{~cm}^{-2}$ is obtained for the $C C M \_\mu M e m 100$ at 3 bar. When micro-patterns $(\mu$ Mem100) are applied to the membrane, the jo value is increased by a factor of 60 at 2 bar which reveals an enhanced distribution of the catalyst on the membrane surface. No significant differences concerning the $\mathrm{j}_{0}$ value are observed between the two MEAs based on a micro-patterned membrane, $C C M \_\mu M e m 50$ and $C C M \_\mu M e m 200$. The $\mu M e m 200$ membrane displays the highest jo value as shown in Table 3, but does not have the highest ratio $\mathrm{A}_{\mathrm{s}} / \mathrm{A}_{\mathrm{g}}$ (as shown in Table 2). Thus, the $\mathrm{j}_{0}$ improvement is not directly related to the surface of the membrane measured by using the optical microscope or the indent depths on the 
membrane. This may be explained by the presence of LIPSS on $\mu$ Mem100, which increases its nano-scale surface that is not detectable using the optical microscope, the real specific aera $A_{s}$ is therefore underestimated.

The $\mathrm{R}_{\text {cell }}$ values given in the Table 3 for a backpressure of 2 bar are $0.38,0.45,0.45,0.85$ and $2 \Omega \mathrm{cm}^{2}$ for

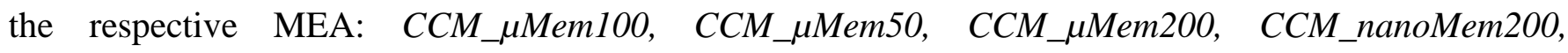
CCM_flatMem. These values mean that the shape of the micro-patterns affects the cell resistivity. $\mathrm{R}_{\text {cell }}$ is decreased by a factor of 5 when micro-patterns are applied to the membrane. These results may come from the local decrease of the membrane thickness with the presence of deep indents or from the enhancement of the water retention capability of the membrane.

In the high density regime (> $500 \mathrm{~mA} \mathrm{~cm}^{-2}$ ), significant voltage drops do not occur. However, an inflection

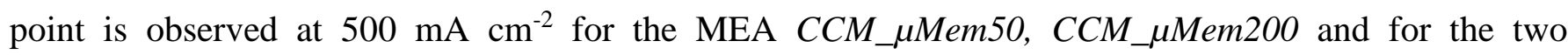
backpressures. This behavior is generally attributed to gas diffusion limitation [34] and could be associated with electrode flooding as it was also observed during the start-up procedure.

The same start-up procedure was performed for the other 5 CCB MEA. The polarization curves of each of them are given in Fig. 6 for the two testing conditions: $50{ }^{\circ} \mathrm{C}$ at 2 bar (a) and $50{ }^{\circ} \mathrm{C}$ at 3 bar (b). For low backpressure, the power density is improved by the presence of the patterning membranes inside the MEA, but the improvement is less significant than in the $\mathrm{CCM}$ architecture cases. For 2 bar and $50{ }^{\circ} \mathrm{C}$, the maximum power density is $334 \mathrm{~mW} \mathrm{~cm}^{-2}$ for the $C C B \_$flatMem and close to $400 \mathrm{~mW} \mathrm{~cm} \mathrm{cor}^{-2}$ foll the other CCB MEA (16\% increase). At low and medium current densities (up to $800 \mathrm{~mA} \cdot \mathrm{cm}^{-2}$ ), no significant differences are visible between the four MEA containing the different patterned membranes. At high current density, gas diffusion limitation can be observed for $C C B \_\mu M e m 50$ and $C C B \_\mu M e m 200$ as the CCM architecture. However, the shape of the patterned membranes seems to mainly affect the catalytic activation. All MEA based on a patterned membrane display the same $\mathrm{j}_{0}$ value which is much higher than the one obtained for the CCB_flatMem MEA (increased factor of 2.5). This confirms the improvement of the catalytic activation with the presence of patterned membrane, even is $R_{\text {cell }}\left(0.3 \mathrm{Ohm} \mathrm{cm}^{2}\right)$ is decreased $(0.35$ 
Ohm $\mathrm{cm}^{2}$ for $C C B \_f l a t M e m$ ). The cell performances of all the patterned MEA reveal an increase of about $30 \%$ at $0.65 \mathrm{~V}$ and the maximum power density is increased by about $15 \%$ in comparison with the CCB_flatMem. The result is rather similar when a backpressure of 3 bar is used during the fuel cell characterization, especially with the nano-patterns (blue curve) which leads to the highest performance. The maximum power density of $C C B \_n a n o M e m 200$ increases by $19 \%$ in comparison to the CCB_flatMem. This result could be attributed to a better matching between the patterns of nanoMem 200 membrane and the shape of the catalyzed GDL surface as mentioned by Chi et al [22].

\section{Conclusion}

This study has presented the effect of membranes patterned on the cathode side of a proton exchange membrane fuel cell. Nano- and micro-patterns were obtained by pressing commercial Nafion NR212 membranes on molds built by laser irradiation. The membranes were associated to a thin catalytic layer obtained by the deposition of an ultralow amount of platinum catalyst $\left(25 \mu \mathrm{g}_{\mathrm{Pt}} \mathrm{cm}^{-2}\right.$ on the cathode interface) by plasma magnetron sputtering. The catalyst is sputtered either on the membrane to form the CCM fuel cell architecture or on the GDL to form the CCB fuel cell architecture. When Pt is deposited on a flat membrane, the loading leads to a catalytic layer thickness of about $15 \mathrm{~nm}$, whereas the depth becomes a few hundred nanometers when Pt is spread on the porous GDL. The fuel cell performance is highly dependent on the morphology of the membrane surface and the MEA architecture (CCM or CCB). When nanometer ripples (coming from the LIPSS observed on the mold) are introduced on the surface of the membrane, the CCM MEA outperforms the conventional one with a flat membrane. For a backpressure of 2 bar and a cell temperature of $50^{\circ} \mathrm{C}$, the maximum power density is increased by a factor of 2 (from 58 to $\left.150 \mathrm{~mW} \mathrm{~cm}^{-2}\right)$. The presence of micro-patterns on the membrane is more profitable $\left(230 \mathrm{~mW} \mathrm{~cm}^{-2}\right.$ for the CCM_uMem200 MEA). By combining micro and nano-patterns (nano-ripples and deep craters on the $\left.C C M \_\mu M e m 100\right)$, the improvement is even better. The maximum power density achieved by such microand nano structured MEA is multiplied by a factor of 3.6 for $50{ }^{\circ} \mathrm{C}$ and $3 \mathrm{bar}: 122 \mathrm{~mW} \mathrm{~cm}{ }^{-2}$ and $438 \mathrm{~mW}$ $\mathrm{cm}^{-2}$ are respectively delivered by the flat membrane based MEA and the $C C M \_\mu M e m 100$ MEA containing 
$25 \mu \mathrm{g}_{\mathrm{Pt}} \mathrm{cm}^{-2}$ at the cathode structured interface. This improvement could be due to a high utilization of the Pt catalyst deposited on the nano- and micro-patterns and to a high conductivity of the structured and catalyzed membrane. For the CCB architecture, the contribution of the patterned membrane to the fuel cell efficiency can also be observed but is less significant. The presence of nanometric ripples seems to increase the fuel cell performance for high pressure.

Further studies such as complex impedance spectroscopy or long time tests will be performed to optimize the relation between surface pattern and fuel cell performance and durability.

\section{Acknowledgements}

Dr T. TILlOCHER, Pr R. DUSSARD, G. COUDRAT, J. SIMONNEAU, Pr E. MILlON and Pr C. BOULMER LEBORGNE are warmly thanked for discussions concerning the patterning of the molds and valuable technical help on the high pressure imprint process.

CEA is acknowledged for a grant. The European commission is acknowledged for funding part of this work through the European Regional Development Fund (ERDF).

\section{References}

[1] M. Mougenot, A. Caillard, P. Brault, S. Baranton, C. Coutanceau, High Performance plasma sputtered PdPt fuel cell electrodes with ultra low loading, International Journal of Hydrogen Energy, 36(14), (2011) $8429-8434$

[2] A. Caillard, C. Charles, R. Boswell, P. Brault, C. Coutanceau, Plasma based platinum nanoaggregates deposited on carbon nanofibers improve fuel cell efficiency, Appl. Phys. Lett. 90 (2007) 223119

[3] M. Cavarroc, A. Ennadjaoui, M. Mougenot, P. Brault, R. Escalier, Y. Tessier, J. Durand, S. Roualdès, T. Sauvage, C. Coutanceau, Performance of plasma sputtered fuel cell electrodes with ultra-low Pt loadings, Electrochemistry Communications 11 (2009) 859-861

[4] S. Cuynet, A. Caillard, P. Brault, J. Bigarré, P. Buvat, High Power Impulse Magnetron Sputtering deposition of Pt inside fuel cell electrodes, J. Phys. D: Appl. Phys. Fast Track Communication 
[5] Cha, S. Y., and W. M. Lee. Performance of proton exchange membrane fuel cell electrodes prepared by direct deposition of ultrathin platinum on the membrane surface, Journal of the Electrochemical Society 146, 11 (1999) 4055-4060.

[6] M.K. Debe, Novel catalysts, catalysts support and catalysts coated membrane methods, in: Handbook of Fuel Cells. John Wiley \& Sons, Ltd. (2010)

[7] R. O’Hayre, S.-J. Lee, S.-W. Cha, F.B. Prinz, A sharp peak in the performance of sputtered platinum fuel cells at ultra-low platinum loading, J. Power Sources 109 (2002) 483-493

[8] L. Sun, R. Ran, G. Wang, Z. Shao, Fabrication and performance test of a catalyst-coated membrane from direct spray deposition, Solid State Ionics 179 (2008) 960-965

[9] S. Wang, G. Sun, G. Wang, Z. Zhou, X. Zhao, H. Sun, X. Fan, B. Yi, Q. Xin, Improvement of direct methanol fuel cell performance by modifying catalyst coated membrane structure, Electrochemistry Communications 7 (2005) 1007-1012

[10] W. C. Choi, J. D. Kim, S.I. Woo, Modification of proton conducting membrane for reducing methanol crossover in direct-methanol fuel cell, Journal of Power Sources 96 (2001) 411-414

[11] M. Prasanna, E.A. Cho, H.-J. Kim, T.-H. Lim, I.-H. Oh, Sung-Ahn Hong, Effects of platinum loading on performance of proton-exchange membrane fuel cells using surface-modified Nafion® membranes, Journal of Power Sources 160 (2006) 90-96

[12] S.A. Cho, E.A. Cho, I.-H. Oh, H.-J. Kim, H.Y. Ha, S.-A. Hong, J.B. Ju, Surface modified Nafion® membrane by ion beam, bombardment for fuel cell applications, Journal of Power Sources 155 (2006) 286290

[13] Y.H. Cho, J.W. Bae, Y.H. Cho, J.W. Lim, M. Ahn, W.-S. Yoon, N.-H. Kwon, J.Y. Jho, Y.-E. Sung, Performance enhancement of membrane electrode assemblies with plasma etched polymer electrolyte membrane in PEM fuel cell, International Journal of Hydrogen Energy 35 (2010) 10452-10456

[14] J.H. Kim, J. Sohn, J.H. Cho, M.Y. Choi, I.G. Koo, W.M. Lee, Surface Modification of Nafion Membranes Using Atmospheric-Pressure Low-Temperature Plasmas for Electrochemical Applications, Plasma Process. Polym. 5 (2008), 377-385 
[15] M. Aizawa and H. Gyoten, Effect of Micro-Patterned Membranes on the Cathode Performances for PEM Fuel Cells under Low Humidity, Journal of The Electrochemical Society, 160 (4), (2013) F417-F428 [16] M. Aizawa, H. Gyoten, A. Salah and X. Liu, Pillar Structured Membranes for Suppressing Cathodic Concentration Overvoltage in PEMFCs at Elevated Temperature/Low Relative Humidity, Journal of The Electrochemical Society, 157 (2010) B1844-B1851

[17] A. D. Taylor, B. D. Lucas, L. J. Guo, L. T. Thompson, Nanoimprinted electrodes for micro-fuel cell applications, Journal of Power Sources 171 (2007) 218-223

[18] M. H. Yildirim, J.T. Braake, H. C. Aran, D.F. Stamatialis, M. Wessling, Micro-patterned Nafion membranes for direct methanol fuel cell applications, Journal of Membrane Science 349 (2010) 231-236

[19] H.-T. Kim, T. V. Reshentenko and H.-J. Kweon, Microstructured Membrane Electrode Assembly for Direct Methanol Fuel Cell, Journal of The Electrochemical Society, 154 (2007) B1034-B1040

[20] A. Omosebi and R. S. Besser, Electron Beam Assisted Patterning and Dry Etching of Nafion Membranes, Journal of The Electrochemical Society, 158 (10), (2011) D603-D610

[21] A. Omosebi, R. S. Besser, Electron beam patterned Nafion membranes for DMFC applications, Journal of Power Sources 228 (2013) 151-158

[22] W. S. Chi, Y. Jeon, S.J. Park, J.H. Kim and Y.-G. Shul, Fabrication of Surface-Patterned Membranes by Means of a ZnO Nanorod Templating Method for Polymer Electrolyte Membrane Fuel-Cell Applications, ChemPlusChem, (2014) 1-8

[23] J. Li, H. Tang, L. Chen, R. Chen, M. Pana and S.P. Jiang, Highly ordered and periodic mesoporous Nafion membranes via colloidal silica mediated self-assembly for fuel cells, Chem. Commun., (2013) 49, 6537

[24] Z. Zhou, R.N. Dominey, J. P. Rolland, B. W. Maynor, A. A. Pandya and J. M. DeSimone, Molded, High Surface Area Polymer Electrolyte Membranes from Cured Liquid Precursors, J. AM. CHEM. SOC. (2006) 128, 12963-12972 
[25] L. Wang, S. G. Advani, and A. K. Prasad, Membrane Electrode Assembly with Enhanced Membrane/Electrode Interface for Proton Exchange Membrane Fuel Cells, J. Phys. Chem. C (2013) 117, 945-948

[26] J. Bonse, R. Koter, M. Hartelt, D. Spaltmann, S. Pentzien, S. Höhm, A. Rosenfeld, J. Krüger, Tribological performance offemtosecond laser-induced periodic surface structures on titanium and a high toughen ss bearing steel, App. Surf. Science (2014).

[27] O. Varlamova, C. Martens, M. Ratzke, J. Reif, Genesis of femtosecond-induced nanostructures on solid surfaces, Appl. optics (2014)

[28] K. Okamuro, M. Hashida, Y. Miyasaka, Y. Ikuta, S. Tokita, S. Sakabe, Laser fluence dependence of periodic grating structures formed on metal surfaces under femtosecond laser pulse irradiation, Physical Review B 82 (2010) 165417.

[29] E.A. Ticianelli, C.R. Derouin, A. Redondo, S. Srinivasan Localization of platinum in low catalyst loading electrodes to attain high power densities in SPE fuel cells, J. Electrochem. Soc. 185 (1988) 2209

[30] S. Hirano, J. Kim, S. Srinivasan, Electrochim. Acta 42 (1997) 1587

[31] A. Y. Vorobyev and Chunlei Guo, Colorizing metals with femtosecond laser pulses, Appl. Phys. Lett. 92, 041914 (2008).

[32] T.T. D. Huynh, N. Semmar, Dependence of ablation threshold and LIPSS formation on copper thin films by accumulative UV picosecond laser shots, Applied Physics A Volume 116, Issue 3, 1429-1435.

[33] W. Dai, H. Wang, X.Z. Yuan, J.J. Martin, D. Yang, J. Qiao, J. Ma, A review on water balance in the membrane electrode assembly of proton exchange membrane fuel cells, International Journal of Hydrogen Energy 34, 23 (2009) 9461-9478.

[34] H. Wang, X.Z. Yuan, H. Li, in : PEM fuel cell diagnostic tools, CRC press (2011), 15-35 17-70 
Table 1. Imprint parameters for the four patterned SS molds.

\begin{tabular}{|c|c|c|c|c|c|}
\hline $\begin{array}{c}\text { Names of } \\
\text { Molds }\end{array}$ & $\begin{array}{c}\text { Name of } \\
\text { patterned } \\
\text { membranes }\end{array}$ & $\begin{array}{c}\text { Laser mean } \\
\text { power }(\mathrm{mW})\end{array}$ & $\begin{array}{c}\text { Step between } \\
\text { each laser spot } \\
(\mu \mathrm{m})\end{array}$ & $\begin{array}{c}\text { Number of } \\
\text { laser pulses on } \\
\text { the same spot }\end{array}$ & $\begin{array}{c}\text { Array size } \\
(\text { spot x spot) }\end{array}$ \\
\hline nanoSS200 & nanoMem200 & 200 & 30 & 1 & $765 \times 765$ \\
\hline$\mu$ SS50 & $\mu$ Mem50 & 50 & 17 & 24 & $1350 \times 1350$ \\
\hline$\mu$ SS100 & $\mu$ Mem100 & 100 & 22 & 21 & $1045 \times 1045$ \\
\hline$\mu$ SS200 & $\mu$ Mem200 & 200 & 30 & 20 & $765 \times 765$ \\
\hline
\end{tabular}

Table 2. Dimensional parameters of the four SS molds and of the four patterned membranes

\begin{tabular}{|c|c|c|c|c|c|}
\hline $\begin{array}{c}\text { Names of } \\
\text { Molds }\end{array}$ & $\begin{array}{c}\text { Laser } \\
\text { crater } \\
\text { diameter } \\
(\mu \mathrm{m})\end{array}$ & Ratio $A_{s /} A_{g}$ & $\begin{array}{c}\text { Name of } \\
\text { patterned } \\
\text { membranes }\end{array}$ & $\begin{array}{c}\text { Bump } \\
\text { height } \\
\text { average } \\
(\mu \mathrm{m})\end{array}$ & Ratio $A_{s /} A_{g}$ \\
\hline nanoSS200 & - & - & nanoMem200 & - & - \\
\hline$\mu$ SS50 & $5-10$ & 2.51 & $\mu$ Mem50 & 11 & 1.51 \\
\hline$\mu$ SS100 & 11 & 2.91 & $\mu$ Mem100 & 14 & 1.60 \\
\hline$\mu$ SS200 & 23 & 3.55 & $\mu$ Mem200 & 24 & 1.89 \\
\hline
\end{tabular}

Table 3. Current exchange density $\mathrm{j}_{0}$ and total resistance $\mathrm{R}_{\text {cell }}$ of the five CCM MEA and of the five CCB MEA for two operating conditions: $50^{\circ} \mathrm{C}$ at 2 bar and $50{ }^{\circ} \mathrm{C}$ at 3 bar.

\begin{tabular}{|c|c|c|c|c|c|}
\hline & \multicolumn{5}{|c|}{$\mathrm{R}_{\text {cell }}\left(\mathrm{Ohm} \mathrm{\textrm {cm } ^ { 2 } )}\right.$} \\
\hline$C C M$ & flatMem & _nanoMem 200 & $\mu \mathrm{Mem50}$ & дMет100 & нMem 200 \\
\hline $50^{\circ} \mathrm{C}$ at 2 bars & 2 & 0.85 & 0.45 & 0.38 & 0.45 \\
\hline $50^{\circ} \mathrm{C}$ at 3 bars & 1.1 & 0.6 & 0.4 & 0.3 & 0.35 \\
\hline$C C B$ & flatMem & nanoMem200 & нMem50 & дMет100 & нMет200 \\
\hline $50^{\circ} \mathrm{C}$ at 2 bars & 0.35 & 0.3 & 0.3 & 0.3 & 0.3 \\
\hline \multirow[t]{2}{*}{$50^{\circ} \mathrm{C}$ at 3 bars } & 0.28 & 0.22 & 0.22 & 0.25 & 0.22 \\
\hline & \multicolumn{5}{|c|}{$j_{0}\left(10^{-9} \mathrm{~A} \mathrm{~cm}^{2}\right)$} \\
\hline$C C M$ & flatMem & _nanoMem200 & $\mu M e m 50$ & $\mu \mathrm{Mem100}$ & дMет200 \\
\hline $50^{\circ} \mathrm{C}$ at 2 bars & 5 & 60 & 160 & 300 & 280 \\
\hline $50^{\circ} \mathrm{C}$ at 3 bars & 200 & 700 & 550 & 800 & 550 \\
\hline$C C B$ & flatMem & _nanoMem200 & $\mu$ Mem50 & _M Mem100 & $\mu \mathrm{Mem} 200$ \\
\hline $50^{\circ} \mathrm{C}$ at 2 bars & 200 & 500 & 500 & 500 & 500 \\
\hline $50^{\circ} \mathrm{C}$ at 3 bars & 600 & 800 & 1000 & 800 & 900 \\
\hline
\end{tabular}




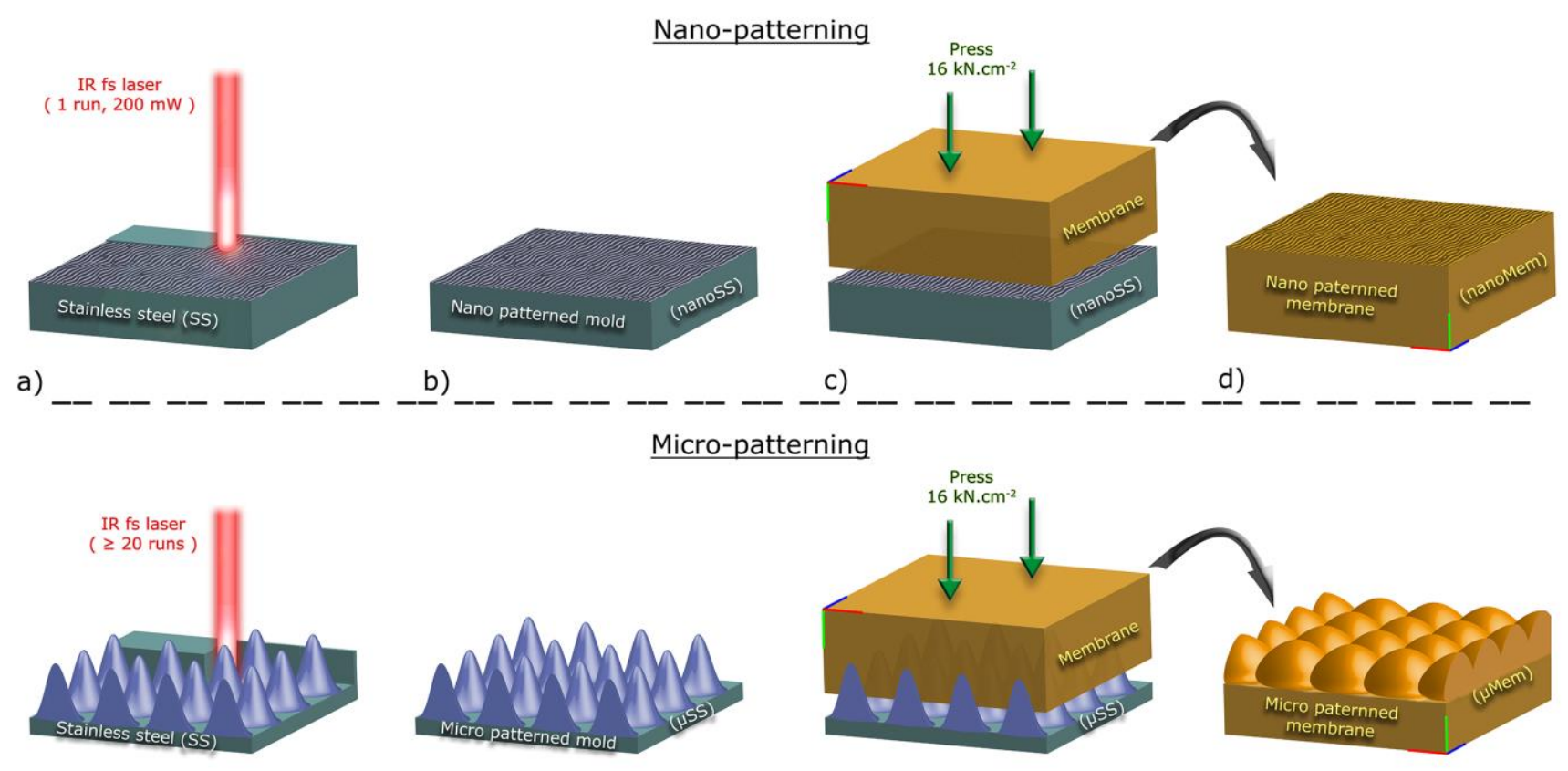

Fig. 1 Fabrication procedure for surface-patterned Nafion membranes. (a) Laser machining on stainless steel surface, (b) patterned mold, (c) pressing operation of the membrane, (d) membrane with patterns. 

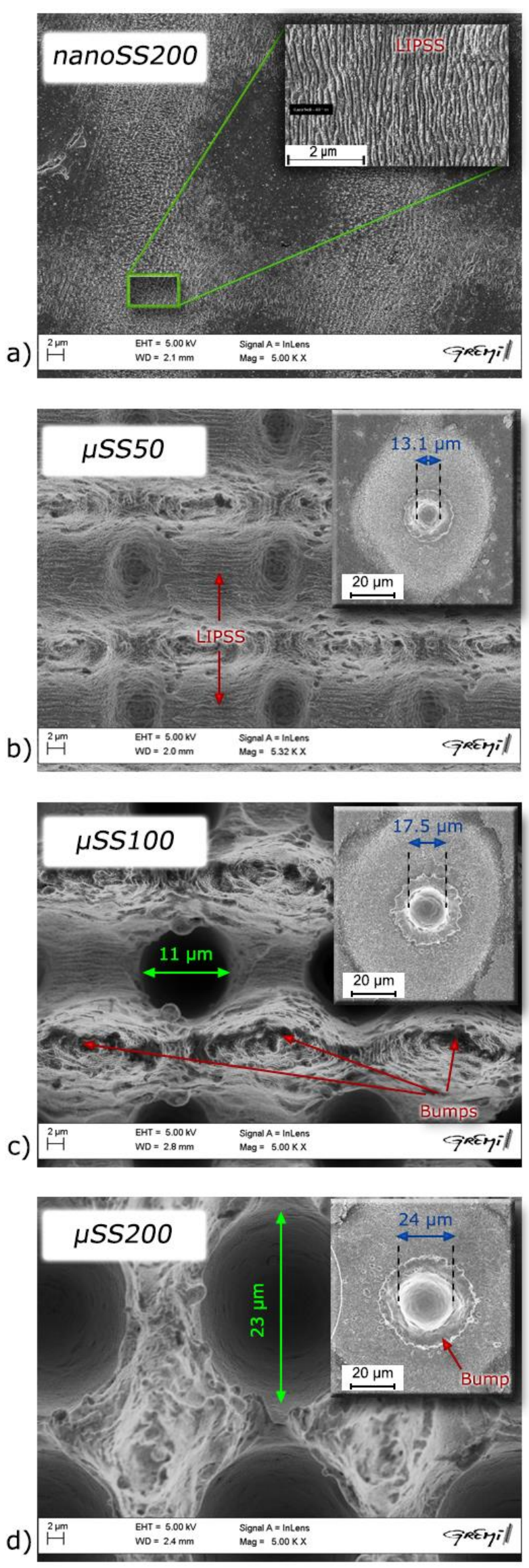

Fig. 2 SEM micrographs of the four SS molds: nanoSS200 (a), $\mu$ SS50 (b), $\mu$ SS100 (c) and $\mu$ SS200 (d). 

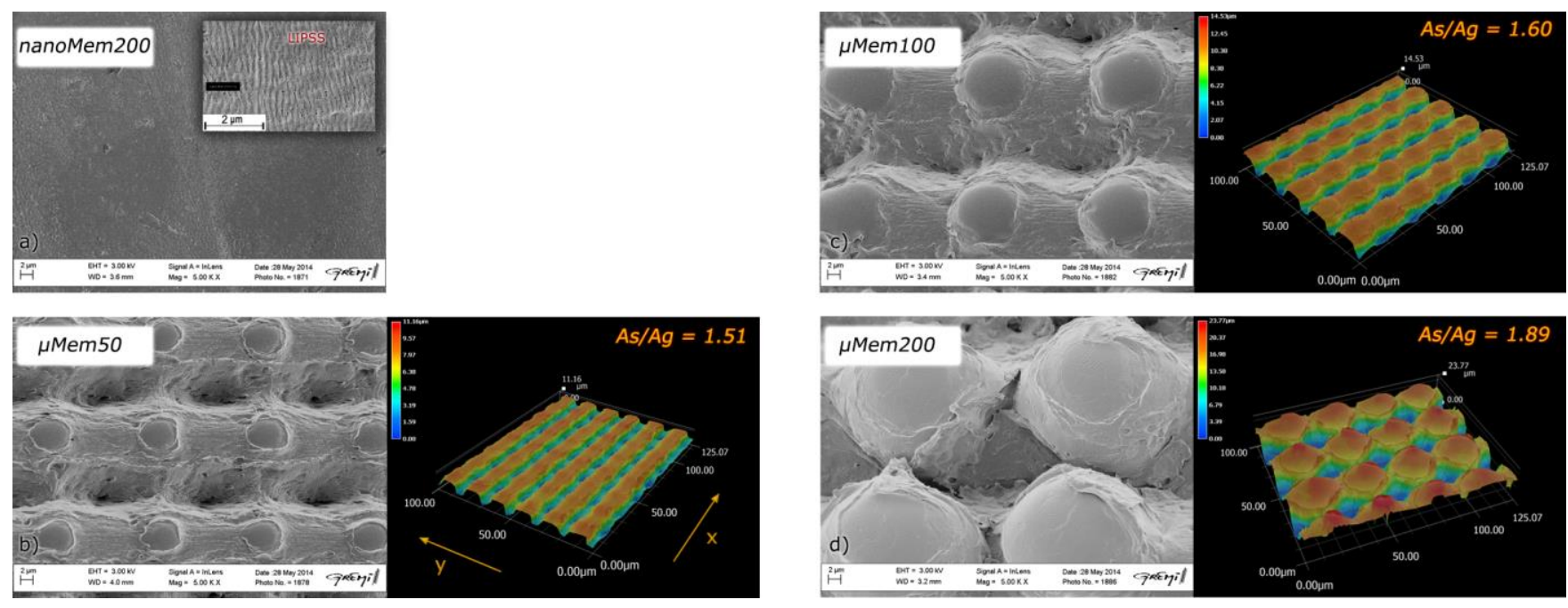

Fig. 3 Micrographs obtained by SEM (left side) and by digital optical microscope (right side, only for $\mu \mathrm{Mem}$ ) of the four patterned membranes: nanoMem200 (a), $\mu \mathrm{Mem50}$ (b), $\mu \mathrm{Mem100}$ (c) and $\mu \mathrm{Mem} 200$ (d).

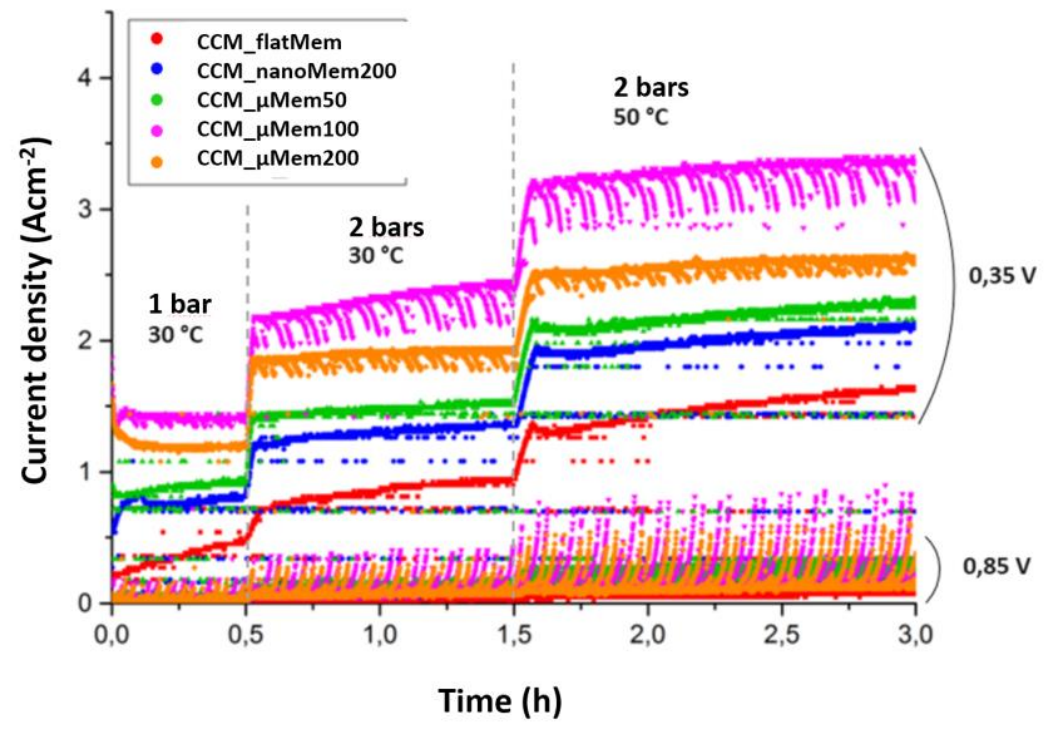

Fig. 4 Current delivered by the five CCM based MEA during the first three operating hours. Four MEA contain nano- and/or micro-patterned NR212 membrane and one MEA (CCM_flatMem) contains one flat NR212 membrane. Experimental conditions: frequency of the electronic load $1 \mathrm{~Hz}$, duty cycle 50\%, low level at $0.35 \mathrm{~V}$ and high level at $0.85 \mathrm{~V}$. 

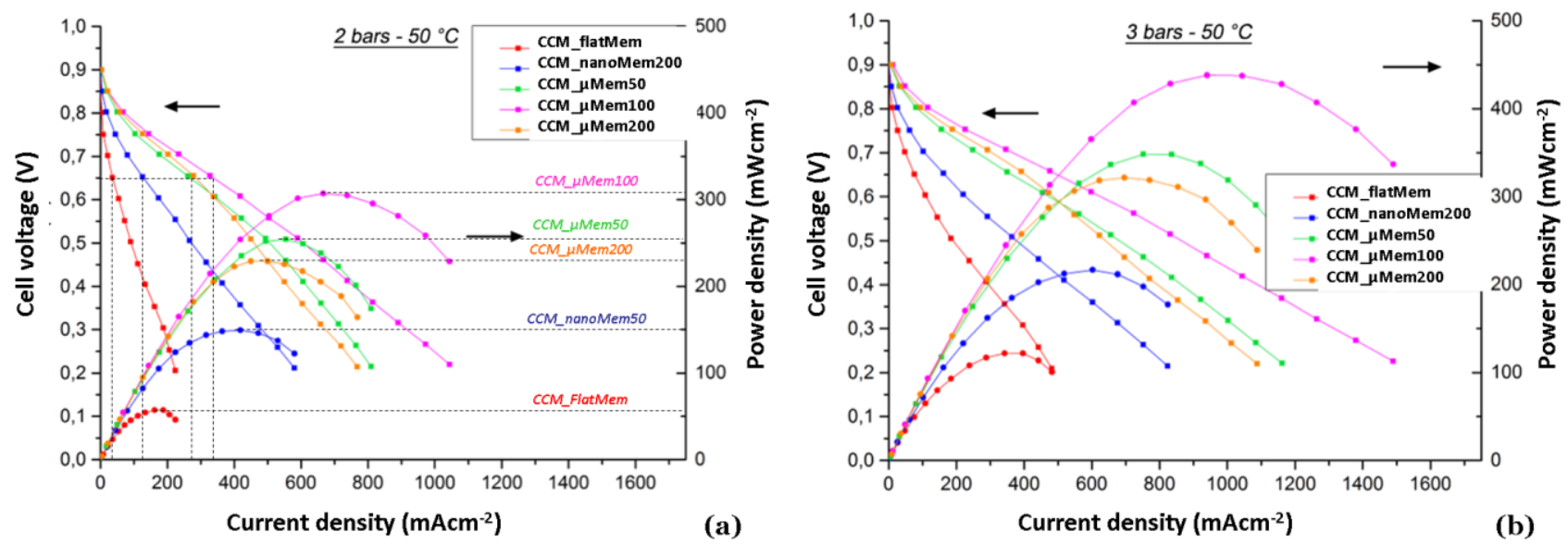

Fig5. $E(j)$ polarizations of the five CCM MEA for two operating conditions : $50{ }^{\circ} \mathrm{C}$ at 2 bars (a) and $50{ }^{\circ} \mathrm{C}$ at 3 bars (b).
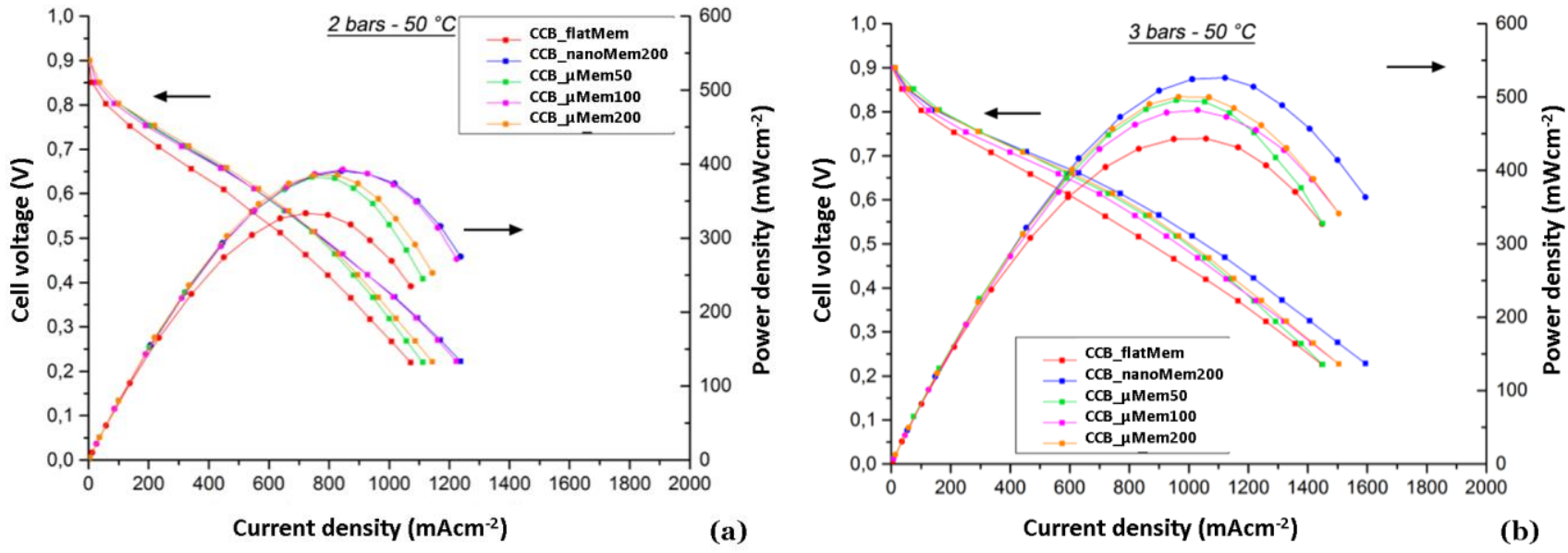

Fig. $6 E(j)$ polarizations of the five $\mathrm{CCB}$ MEA for two operating conditions : $50{ }^{\circ} \mathrm{C}$ at 2 bars (a) and $50{ }^{\circ} \mathrm{C}$ at 3 bars (b). 